\title{
Hemodynamic Changes during Off-Pump Coronary Artery Bypass Graft Surgery: Experience Using Pericardial Bands for Target Stabilization
}

\author{
Srikrishna Sirivella, Isaac Gielchinsky \\ Department of Cardiovascular and Thoracic Surgery, Newark Beth Israel Medical Center, \\ University of Medicine \& Dentistry of New Jersey, Newark, USA \\ Email: igielchinsky@optonline.net
}

Received November 4, 2013; revised December 4, 2013; accepted December 10, 2013

Copyright (C) 2013 Srikrishna Sirivella, Isaac Gielchinsky. This is an open access article distributed under the Creative Commons Attribution License, which permits unrestricted use, distribution, and reproduction in any medium, provided the original work is properly cited. In accordance of the Creative Commons Attribution License all Copyrights (C) 2013 are reserved for SCIRP and the owner of the intellectual property Srikrishna Sirivella, Isaac Gielchinsky. All Copyright (C 2013 are guarded by law and by SCIRP as a guardian.

\begin{abstract}
Background: The off-pump coronary artery bypass graft surgery (OPCAB) may produce significant hemodynamic instability necessitating conversion to on-pump surgery. This study evaluated the hemodynamic parameters in patients undergoing OPCAB using pericardial bands for stabilization of the coronary target sites. Methods: In 250 patients undergoing $\mathrm{OPCAB}$ the hemodynamic parameters including continuous cardiac output and systemic venous oxygen saturation $\left(\mathrm{SvO}_{2}\right)$ were recorded at baseline after pericardiotomy, during each coronary artery anastomosis at $3,5,10,15$ $\mathrm{min}$, and after release of the pericardial bands used for target stabilization. Vasopressors were used to maintain mean arterial pressure (MAP) $>60 \mathrm{mmHg}$. Results: $\mathrm{SvO}_{2}$ and cardiac index (CI) decreased significantly after target stabilization and during all coronary anastomoses with greater decreases noted during obtuse marginal branch of left circumflex $(\mathrm{OM})$ anastomosis. The MAP and heart rate were maintained without significant change but central venous pressure increased significantly during all coronary anastomoses. The significant increase in pulmonary capillary wedge pressure and mean pulmonary artery pressure were noted only during anastomosis of the left anterior descending artery. The highest dose of vasopressor was used during OM anastomosis. Conclusions: During OPCAB surgery using pericardial bands for coronary target stabilization, MAP was maintained constantly, but $\mathrm{SvO}_{2}$ and CI decreased immediately after target stabilization and reduced further during all coronary artery anastomoses. During $\mathrm{OM}$ anastomosis $\mathrm{SvO}_{2}$ and $\mathrm{CI}$ were significantly lower as compared to that of LAD and right coronary artery. Careful monitoring and management of hemodynamic variables are warranted to avoid conversion to on-pump technique.
\end{abstract}

Keywords: Circulatory Hemodynamics; CABG; New Technology; Off-Pump Surgery

\section{Introduction}

The off-pump coronary artery bypass graft surgery (OP$\mathrm{CAB}$ ) is being expanded in recent years because of the advantage of avoiding cardiopulmonary bypass (CPB) and its attendant complications, improvements in techniques as well as recent introduction of instruments to optimally stabilize the coronary targets on a beating heart. [1-5]. The introduction of mechanical stabilizers such as CTS pressure mechanical stabilizers, epicardial fixation by suction devices and the Medtronic-Utrecht Octopus system, (Medtronic Inc, Minneapolis, MN), produced adequate cardiac immobilization of the coronary target site for performance of a safe anastomosis [6]. However, the hemodynamic instability that occurs during positioning of the heart and stabilization of the coronary targets with interruption of coronary blood flow are important factors limiting the safe performance of OPCAB. Several studies have been performed noting the changes in hemodynamic parameters and management of hemodynamic instability during $\mathrm{OPCAB}$ using mechanical stabilizers for coronary target stabilization and hemodynamic variables measured in most of these studies were either sparse or were measured only once during procedure without noting the progress of hemodynamic change dur- 
ing coronary artery anastomosis $[7,8]$. This study evaluated the use of pericardial bands for coronary target stabilization, noting serial hemodynamic parameters recorded during coronary artery anastomoses.

\section{Material and Methods}

During a three year period 250 patients with coronary artery disease participated in this prospective study and all were planned to undergo OPCAB. Patients with significant preoperative hepatic or renal dysfunction, bleeding disorder or uncontrolled arrhythmia were excluded. The characteristics of this patient group are shown in Table 1. This study was approved by the institutional review board and ethics committee of the NWBIMC and informed consent was obtained from all patients.

\subsection{Surgical Technique}

All preoperative cardiac medications were continued till the morning of surgery, but digoxin was withheld. Morphine sulphate $0.05 \mathrm{mg} / \mathrm{kg} \mathrm{IM}$ was given an hour before the surgery as premedication. In the operating room, EKG leads II and V5 were monitored and the radial artery was cannulated for continuous monitoring of arterial blood pressure and blood gas analysis. Anesthetic induction was done with $2.0-3.0 \mathrm{mg}$ of midazolam, $1.0-3.0$ $\mu \mathrm{g} / \mathrm{kg}$ of sufentanil, and $50 \mathrm{mg}$ of rocuronium. Anaesthesia was maintained with $0.2-0.5 \mathrm{vol} \%$ of isoflurane and

Table 1. Patient Demographics.

\begin{tabular}{lcc}
\hline \multicolumn{1}{c}{ Variable } & Number & Percentage (\%) \\
\hline Age (years) & $56 \pm 9^{*}$ & \\
Sex (M/F) & $200 / 50$ & $80 / 20$ \\
Co-morbidity: & & \\
$\quad$ Diabetes mellitus & 88 & 35 \\
$\quad$ Hypertension & 75 & 30 \\
$\quad$ Prior myocardial infarction & 50 & 20 \\
$\quad$ Prior stroke/TIA & 38 & 15 \\
Preoperative medications: & & \\
$\quad$ ACE inhibitors & 120 & 48 \\
$\quad$ Beta blockers & 225 & 90 \\
Calcium channel blockers & 212 & 85 \\
Coronary artery disease & & \\
Left main and 2 or 3 vessel & 25 & 10 \\
3 Vessel disease & 207 & 82 \\
2 vessel disease & 18 & 7 \\
Echocardiography: & & \\
Wall motion abnormalities: & & \\
Regional akinesia & 56 & 90 \\
Regional hypokinesia & 225 & \\
Ejection fraction & $57.3 \pm 11.4^{*}$ & \\
\hline * & & \\
\hline
\end{tabular}

${ }^{*}$ Mean value and \pm SD (standard deviation), TIA $=$ transient ischemic event. continuous intravenous infusion of $0.5-1.5 \mu \mathrm{g} / \mathrm{kg} / \mathrm{min}$ of sufentanil and vecuronium. Ventilation was controlled with oxygen-air mixture $\left(\mathrm{FiO}_{2} \mathrm{0.6}\right)$ to maintain end-tidal $\mathrm{CO}_{2}$ in $35-38 \mathrm{mmHg}$. After anaesthetic induction isosorbide dinitrate infusion at $0.5 \mu \mathrm{g} / \mathrm{kg} / \mathrm{min}$ and diltiazem infusion at $1 \mathrm{mcg} / \mathrm{kg} / \mathrm{min}$ were started and the SwanGanz catheter (Swan-Ganz, Baxter Healthcare Co., Irvine, CA, USA) was inserted through the right internal jugular vein into the main pulmonary artery. The temperature of the operating room was kept above $25^{\circ} \mathrm{C}$ and all the fluid (infusions and irrigations) was warmed to prevent hypothermia. Warm humidifier was connected to the breathing circuit. Patients were also warmed with warm mattress and after the venous harvest; the lower limbs were wrapped with ace bandage and covered with a warm blanket.

After median sternotomy, adequate amount of fluid (1.5 - 2.0 litters) was administered to keep the CVP around $10 \mathrm{~mm} \cdot \mathrm{Hg}$. After dissection of left internal mammary artery (LIMA), and harvesting 3 pericardial bands intravenous heparin was injected $(1 \mathrm{mg} / \mathrm{kg})$ and activated clotting time was maintained over $250 \mathrm{~s}$ during the coronary anastomoses. To expose the left lateral side of the heart and to elevate the apex, four deep pericardial stay sutures were placed at aorto-pericardial reflection, left superior and inferior pulmonary veins and between left inferior pulmonary veins and inferior vena cava [9]. Traction on these stay sutures positioned the heart to expose the coronary artery target, and then appropriate pericardial bands were snared for stabilization of the coronary targets for anastomosis. The technique of harvesting the pericardial bands and coronary target stabilization using pericardial bands was as described earlier [10]. Briefly, this technique involved fashioning 3 pericardial bands of $2.5 \mathrm{~cm}$ wide and 8 to $10 \mathrm{~cm}$ long from the body of the anterior pericardium after median sternotomy incision was completed. Two pericardial bands are positioned one above and one below the coronary target and the distal ends of the bands were snared to the pericardial well for stabilization of the anastomotic site. Trendelenburg position was often employed during anastomosis. In case of hypotension, nor-epinephrine was given to maintain mean systemic arterial pressure (MAP) above $60 \mathrm{mmHg}$. In this study (250 patients) an average of $2.8 \pm 0.7$ coronary arteries were bypassed in a patient. The time for performing three coronary artery anastomoses was $48 \pm 12$ min (mean). The time required to anastomose each coronary artery are following: $17.6 \pm 3.4 \mathrm{~min}$ for LAD, 17.6 \pm 1.8 min for obtuse marginal branch of LCX and $17.9 \pm$ $1.8 \mathrm{~min}$ for RCA.

\subsection{Hemodynamic Monitoring}

The hemodynamic variables recorded were heart rate (HR), central venous right atrial pressure (CVP), systemic mean 
arterial pressure (MAP), pulmonary artery pressure (PAP), pulmonary capillary wedge pressure (PCWP), cardiac output $(\mathrm{CO})$, and systemic venous oxygen saturation $\left(\mathrm{SvO}_{2}\right)$. The cardiac index $(\mathrm{CI})$, stroke volume index (SVI), left ventricular stroke work index (LVSWI), and systemic and pulmonary vascular resistances were calculated according to standard formulas. Hemodynamic measurements were recorded after pericardiotomy for baseline value, then $3,5,10$, and $15 \mathrm{~min}$ after snaring the pericardial bands for coronary artery target stabilization during each coronary artery anastomosis, after the removal of the bands and after sternal closure. The amount of nor-epinephrine used to maintain MAP for each anastomosis was also recorded.

\subsection{Statistical Analysis}

All hemodynamic variables were expressed as the mean value \pm SD. Hemodynamic changes for each coronary graft anastomosis were compared to baseline values using repeated measures of analysis of variance (ANOVA). The comparisons of variables between coronary arteries were analyzed with one-way ANOVA. Percent changes of $\mathrm{CI}$ and $\mathrm{SvO}_{2}$ for baseline values in each coronary artery were analyzed with linear regression. A $\mathrm{P}$ value of $<0.05$ was considered as statistically significant. Data were analyzed with SPSS for Windows, release 10.0 (SPSS Inc., Chicago, IL, USA).

\section{Results}

During RCA anastomosis, the HR was significantly in- creased throughout the procedure (T3 to T15 and at sterna closure) compared to the baseline value, but MAP decreased only initially at T3. The MPAP and PCWP did not show significant change compared with baseline, except a brief elevation of PCWP at T3. The CVP at T3 to T15 significantly increased and the $\mathrm{CI}, \mathrm{SvO}_{2}, \mathrm{SVI}$ and LVSWI at T3 to T15 significantly decreased compared with baseline. The SVRI did not change compared with baseline except increase at T10.

During obtuse marginal branch of LCX anastomosis, the HR at T3 to T10 and at sternal closure (Ts), signifycantly increased, but without any change in MAP. The CVP at T3 to T15 and PCWP at T10 to T15 significantly increased compared with baseline values. The cardiac index (CI), $\mathrm{SvO}_{2}, \mathrm{SVI}$, and LVSWI showed significant decrease at T3 to T15 compared with baseline. The SVRI at T3 to T15, significantly increased compared with baseline values

During LAD anastomosis, the HR was significantly increased only at sternal closure without a change in MAP. The CVP, MPAP, PCWP significantly increased from $\mathrm{T} 3$ to $\mathrm{T} 15$ compared with the baseline values. The $\mathrm{CI}, \mathrm{SvO}_{2}, \mathrm{SVI}$, and LVSWI were significantly decreased from T3 through T15 and SVRI was significantly increased at T15 compared with baseline values. Hemodynamic data during coronary artery bypass graft anastomoses are shown in Tables $\mathbf{2}$ and $\mathbf{3}$.

On comparing variables between the 3 coronary artery anastomoses, no differences were noted in HR, MAP and CVP during entire period of surgery (B to Ts). MPAP was significantly lower in $\mathrm{OM}$ at $\mathrm{T} 3$, and in RCA at T3

Table 2. Hemodynamic data during coronary artery bypass graft anastomosis. (Mean \pm SD).

\begin{tabular}{|c|c|c|c|c|c|c|c|c|}
\hline Var & Art & B & T3 & T5 & T10 & T15 & $\mathbf{T r}$ & Tst \\
\hline \multirow[t]{3}{*}{ HR } & $\mathrm{RC}$ & $61 \pm 10$ & $69 \pm 10^{*}$ & $68 \pm 10^{*}$ & $68 \pm 11^{*}$ & $67 \pm 10^{*}$ & $68 \pm 10^{*}$ & $69 \pm 12^{*}$ \\
\hline & OM & $61 \pm 10$ & $66 \pm 14^{*}$ & $65 \pm 14^{*}$ & $65 \pm 13^{*}$ & $63 \pm 12$ & $64 \pm 11$ & $70 \pm 12^{*}$ \\
\hline & LA & $61 \pm 10$ & $64 \pm 12$ & $63 \pm 12$ & $63 \pm 13$ & $62 \pm 12$ & $62 \pm 10$ & $70 \pm 12^{*}$ \\
\hline \multirow[t]{3}{*}{ CVP } & $\mathrm{RC}$ & $6 \pm 5$ & $12 \pm 4^{*}$ & $11 \pm 4^{*}$ & $11 \pm 3^{*}$ & $11 \pm 4^{*}$ & $9 \pm 3$ & $9 \pm 3$ \\
\hline & OM & $6 \pm 4$ & $11 \pm 4^{*}$ & $11 \pm 4^{*}$ & $11 \pm 4^{*}$ & $11 \pm 5^{*}$ & $9 \pm 3$ & $8 \pm 3$ \\
\hline & LA & $6 \pm 4$ & $11 \pm 4^{*}$ & $11 \pm 4^{*}$ & $11 \pm 4^{*}$ & $11 \pm 5^{*}$ & $9 \pm 3$ & $9 \pm 3$ \\
\hline \multirow[t]{3}{*}{ MAP } & $\mathrm{RC}$ & $85 \pm 12$ & $76 \pm 8^{*}$ & $80 \pm 9$ & $80 \pm 10$ & $82 \pm 9$ & $79 \pm 13$ & $84 \pm 13$ \\
\hline & OM & $85 \pm 12$ & $83 \pm 9$ & $81 \pm 9$ & $80 \pm 10$ & $80 \pm 12$ & $83 \pm 13$ & $84 \pm 13$ \\
\hline & LA & $85 \pm 12$ & $84 \pm 12$ & $81 \pm 11$ & $80 \pm 12$ & $81 \pm 10$ & $82 \pm 11$ & $84 \pm 13$ \\
\hline \multirow[t]{3}{*}{ MPAP } & $\mathrm{RC}$ & $16 \pm 7$ & $21 \pm 7$ & $21 \pm 5^{* *}$ & $21 \pm 7$ & $20 \pm 6^{* *}$ & $20 \pm 6$ & $20 \pm 4$ \\
\hline & OM & $16 \pm 6$ & $20 \pm 7^{* *}$ & $22 \pm 6$ & $22 \pm 7$ & $22 \pm 7$ & $21 \pm 7$ & $20 \pm 5$ \\
\hline & LA & $16 \pm 6$ & $24 \pm 7^{*}$ & $25 \pm 7^{*}$ & $24 \pm 7^{*}$ & $24 \pm 7^{*}$ & $22 \pm 6$ & $20 \pm 5$ \\
\hline \multirow[t]{2}{*}{ PCWP } & $\mathrm{RC}$ & $10 \pm 4$ & $15 \pm 4^{*}$ & $14 \pm 4$ & $14 \pm 4$ & $14 \pm 4$ & $14 \pm 4$ & $14 \pm 4$ \\
\hline & $\mathrm{OM}$ & $10 \pm 4$ & $14 \pm 4$ & $14 \pm 4$ & $15 \pm 4^{*}$ & $15 \pm 5^{*}$ & $14 \pm 5$ & $14 \pm 5$ \\
\hline \multirow[t]{3}{*}{$\mathrm{SvO}_{2}$} & $\mathrm{RC}$ & $83 \pm 5$ & $73 \pm 9^{*}$ & $70 \pm 9^{*}$ & $70 \pm 9^{*}$ & $70 \pm 10^{*}$ & $72 \pm 11^{*}$ & $76 \pm 7^{*}$ \\
\hline & OM & $83 \pm 5$ & $72 \pm 9^{*}$ & $68 \pm 9^{* *}$ & $68 \pm 9$ & $67 \pm 10^{* *}$ & $70 \pm 11$ & $76 \pm 7^{*}$ \\
\hline & LA & $83 \pm 5$ & $76 \pm 8^{*}$ & $73 \pm 10^{*}$ & $74 \pm 11^{*}$ & $73 \pm 11^{*}$ & $74 \pm 8^{*}$ & $76 \pm 7^{*}$ \\
\hline
\end{tabular}

$\mathrm{Hr}$, heart rate (beats/minute); CVP, central venous pressure $(\mathrm{mm} \cdot \mathrm{Hg})$; MAP, mean systemic artertial pressure $(\mathrm{mm} \cdot \mathrm{Hg})$; MPAP, mean pulmonary arterial pressure $(\mathrm{mm} \cdot \mathrm{Hg})$; PCWP, pulmonary capillary wedge pressure $(\mathrm{mm} \cdot \mathrm{Hg}) ; \mathrm{SvO}_{2}$, systemic mixed venous oxygen saturation(\%); LA, left anterior descending coronary artery; OM, obtuse marginal branch of left circumflex coronary artery; RC, right coronary artery or posterior descending coronary artery; Var, variable; Art, artery; B,baseline; T3, 3 minutes;T5, 5 minutes; T10, 10 minutes; T15, 15 minutes after application of pericardial bands for coronary target stabilization, Tr, after release of pericardial bands used for coronary target stabilization. T st, after strenal closure. ${ }^{*} \mathrm{p}<0.05$ compared to baseline value. ${ }^{* *} \mathrm{p}<0.05$ compared to LAD branch. 
Table 3. Calculated hemodynamic data during coronary artery bypass graft anastomosis. (Mean \pm SD).

\begin{tabular}{|c|c|c|c|c|c|c|c|c|}
\hline Var & Ar & B & T3 & T5 & T10 & T15 & $\operatorname{Tr}$ & Tst \\
\hline \multirow[t]{3}{*}{ CI } & $\mathrm{Rc}$ & $2.8 \pm 0.6$ & $2.4 \pm 0.6^{*}$ & $2.1 \pm 0.6^{*}$ & $2.1 \pm 0.6$ & $2.2 \pm 0.5^{*}$ & $2.2 \pm 0.6^{*}$ & $2.9 \pm 0.6$ \\
\hline & Om & $2.8 \pm 0.6$ & $2.0 \pm 0.6^{*}$ & $1.9 \pm 0.5^{* *}$ & $1.9 \pm 0.5^{* *}$ & $1.9 \pm 0.4$ & $2.0 \pm 0.5$ & $2.9 \pm 0.6$ \\
\hline & $\mathrm{La}$ & $2.8 \pm 0.6$ & $2.3 \pm 0.7^{*}$ & $2.3 \pm 0.5^{*}$ & $2.3 \pm 0.5^{*}$ & $2.2 \pm 0.5^{*}$ & $2.1 \pm 0.4^{*}$ & $2.8 \pm 0.6$ \\
\hline \multirow[t]{3}{*}{ SWI } & $\mathrm{Rc}$ & $46 \pm 9$ & $34 \pm 9^{*}$ & $32 \pm 9^{*}$ & $32 \pm 9^{*}$ & $33 \pm 7^{*}$ & $34 \pm 11^{*}$ & $42 \pm 8^{*}$ \\
\hline & Om & $46 \pm 9$ & $31 \pm 9^{* * *}$ & $30 \pm 10^{* * *}$ & $31 \pm 10^{* * *}$ & $30 \pm 8^{*}$ & $32 \pm 10^{*}$ & $42 \pm 8^{*}$ \\
\hline & $\mathrm{La}$ & $46 \pm 11$ & $39 \pm 10^{*}$ & $39 \pm 11^{*}$ & $38 \pm 9^{*}$ & $36 \pm 8^{*}$ & $36 \pm 8^{*}$ & $42 \pm 8^{*}$ \\
\hline \multirow[t]{3}{*}{ LVSWI } & $\mathrm{Rc}$ & $43 \pm 10$ & $31 \pm 9^{*}$ & $28 \pm 8^{*}$ & $27 \pm 8^{*}$ & $30 \pm 6^{*}$ & $30 \pm 10^{*}$ & $39 \pm 9$ \\
\hline & Om & $43 \pm 10$ & $30 \pm 8^{*}$ & $27 \pm 10^{*}$ & $27 \pm 9^{*}$ & $27 \pm 7^{*}$ & $29 \pm 10^{*}$ & $39 \pm 9$ \\
\hline & $\mathrm{La}$ & $43 \pm 10$ & $34 \pm 9$ & $31 \pm 8^{*}$ & $32 \pm 9^{*}$ & $30 \pm 9^{*}$ & $31 \pm 9^{*}$ & $39 \pm 9$ \\
\hline \multicolumn{2}{|c|}{ SVRI } & \multicolumn{2}{|r|}{$\mathrm{Rc}$} & \multicolumn{3}{|c|}{$\mathrm{Om}$} & \multicolumn{2}{|c|}{$\mathrm{La}$} \\
\hline \multicolumn{2}{|c|}{ B } & \multicolumn{2}{|r|}{$2295 \pm 615$} & \multicolumn{3}{|c|}{$2295 \pm 615$} & \multicolumn{2}{|c|}{$2295 \pm 615$} \\
\hline \multicolumn{2}{|c|}{ T3 } & \multicolumn{2}{|r|}{$2735 \pm 762$} & \multicolumn{3}{|c|}{$3102 \pm 960^{* *}$} & \multicolumn{2}{|c|}{$2514 \pm 729$} \\
\hline \multicolumn{2}{|c|}{ T5 } & \multicolumn{2}{|r|}{$2729 \pm 672$} & \multicolumn{3}{|c|}{$3179 \pm 932^{* *}$} & \multicolumn{2}{|c|}{$2529 \pm 572$} \\
\hline \multicolumn{2}{|c|}{ T10 } & \multicolumn{2}{|r|}{$2853 \pm 612^{*}$} & \multicolumn{3}{|c|}{$3194 \pm 979^{* *}$} & \multicolumn{2}{|c|}{$2534 \pm 512$} \\
\hline \multicolumn{2}{|c|}{ T15 } & \multicolumn{2}{|r|}{$2769 \pm 672$} & \multicolumn{3}{|c|}{$3144 \pm 872^{* *}$} & \multicolumn{2}{|c|}{$2592 \pm 482^{*}$} \\
\hline \multicolumn{2}{|c|}{$\operatorname{Tr}$} & \multicolumn{2}{|r|}{$2722 \pm 812$} & \multicolumn{3}{|c|}{$3232 \pm 992^{* *}$} & \multicolumn{2}{|c|}{$2652 \pm 622^{*}$} \\
\hline \multicolumn{2}{|c|}{ Tst } & \multicolumn{2}{|r|}{$2185 \pm 612$} & & \multicolumn{2}{|l|}{$2185 \pm 612$} & \multicolumn{2}{|c|}{$2185 \pm 612$} \\
\hline
\end{tabular}

CI, cardiac index (liters $\left./ \mathrm{min}^{2}\right)$; SWI, stroke work index $\left(\mathrm{ml} /\right.$ beat $\left./ \mathrm{m}^{2}\right)$; LVSWI, left ventricular stroke work index (gm/ $\left.\mathrm{m}^{2}\right)$; SVRI, systemic vascular resistance index, $\left(\right.$ dynes $\mathrm{cm}^{-5} / \mathrm{m}^{2}$ ); La, left anterior descending coronary artery; Om, obtuse marginal branch of left circumflex coronary artery; Rc, right coronary artery or posterior descending coronary artery; T3, 3 minutes; T5, 5 minutes; T10, 10 minutes; T15, 15 minutes after application of pericardial bands for coronary target stabilization, Tr, after release of pericardial bands used for coronary target stabilization. T st, after strenal closure. ${ }^{*} \mathrm{p}<0.05$ compared to baseline value, ${ }^{* *} \mathrm{p}<$ 0.05 compared to LAD branch, ${ }^{* * *} \mathrm{p}<0.05$ compared to both baseline and LAD.

and $\mathrm{T} 10$ as compared to LAD. The CI and $\mathrm{SvO}_{2}$ from T3 to T15 were significantly lower in OM as compared to LAD. The SVI was significantly lower in OM than in LAD from T3 to T10. The LVSWI of LAD at T3 was higher than that of OM and RCA. The SVRI was significantly higher in OM form $\mathrm{T} 3$ to $\mathrm{Tr}$ compared to LAD. The changes of $\mathrm{CI}$ and $\mathrm{SvO}_{2}$ of each coronary artery were compared. The decrease in CI was greater in OM compared to that of LAD (Figure 1). Similarly the decrease in $\mathrm{SvO}_{2}$ was greater in OM compared to that of LAD (Figure 2). Noticeably, the change of CI in LAD showed linear decrease with time though the change of $\mathrm{CI}$ in $\mathrm{OM}$ and RCA did not show the same pattern. The total doses of nor-epinephrine used to maintain MAP over $60 \mathrm{mmHg}$ during performance of anastomoses were $87.1 \pm 106.4,74.0 \pm 60.9$ and $216.9 \pm 282.6 \mu \mathrm{g}$ for $\mathrm{LAD}$, RCA, and OM vessels respectively. The amount of norepinephrine used was significantly larger in OM than in other two arteries.

\section{Comment}

Though during earlier years, the OPCAB surgery was performed in patients with good ventricular function and a single or two-vessel disease, this has been recently performed in patients with calcified and atheromatous ascending aorta, renal failure, cerebrovascular disease, or in patients with poor ventricular function or advanced heart failure for avoiding CPB-related complications [11]. The hemodynamic deterioration occurring during coronary anatomosis is an important concern of OPCAB pro-

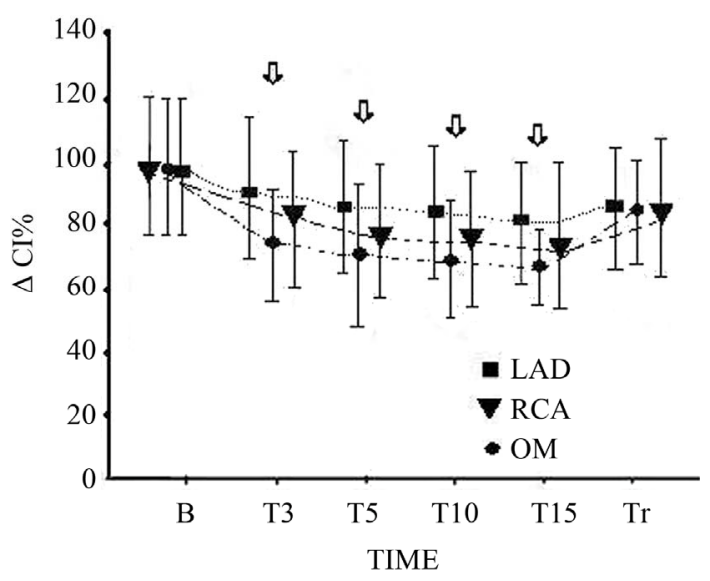

Figure 1. The changes in cardiac index during each coronary graft anastomosis. $\Delta \mathrm{CI} \%=$ (cardiac index for each period/baseline cardiac index $) \times 100$. The vertical bars represent standard deviation. $B=$ baseline after pericardiotomy, T3 = 3minutes after stabilization of a coronary target. T5 = 5 minutes after stabilization of a coronary target, T10 $=10$ minutes after stabilization of a coronary target, $T 15=$ 15 minutes after stabilization of a coronary target, $T r=$ after release of pericardial bands used for stabilization of a coronary target and post grafting period. $L A D=$ left anterior descending coronary artery, $\mathrm{RCA}=$ right coronary artery, $O M=$ obtuse marginal branch of left circumflex coronary artery, the white arrows indicate $p<0.05$ compared to LAD.

cedure. This study evaluated the hemodynamic variables during coronary artery anastomoses using deep pericardial stay sutures and pericardial bands for coronary artery target stabilization and all hemodynamic variables were 


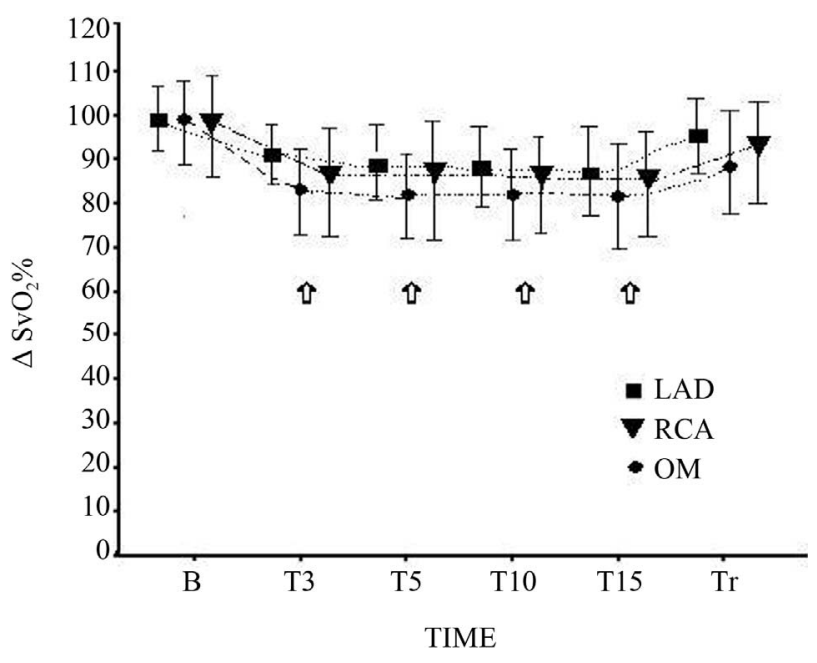

Figure 2. The changes in mixed venous oxygen saturation $\left(\mathrm{SvO}_{2}\right)$ during each coronary graft anastomosis. $\Delta \mathrm{SvO}_{2} \%=$ $\left(\mathrm{SvO}_{2}\right.$ for each period/baseline $\left.\mathrm{SvO}_{2}\right) \times 100$. The vertical bars represent standard deviation. $B=$ baseline after pericardiotomy, $T 3=3$ minutes after stabilization of a coronary target. $T 5=5$ minutes after stabilization of a coronary target, $\mathrm{T10}=10$ minutes after stabilization of a coronary target, $\mathrm{T} 15=15$ minutes after stabilization of a coronary target, $\mathrm{Tr}=$ after release of pericardial bands used for stabilization of a coronary target and post grafting period. $\mathrm{LAD}=$ left anterior descending coronary artery, $\mathrm{RCA}=$ right coronary artery, $\mathrm{OM}=$ obtuse marginal branch of left circumflex coronary artery. The white arrows indicate $p<$ 0.05 compared to LAD.

recorded as a function of time during each coronary artery anastomosis. After the initial hemodynamic change induced by the heart positioning and snaring the pericardial bands to the pericardial well, no further significant hemodynamic deterioration or improvement were noticed. There was no case that could not perform planned anastomosis or convert to CPB due to hemodynamic instability. Though incidence of emergency conversion during OPCAB has decreased with increasing surgical experience, outcomes in these patients continued to be worse than those in non-converted patients. Therefore, careful monitoring of hemodynamic changes and safer bail out strategies are still warranted [12].

The $\mathrm{CI}$ and $\mathrm{SvO}_{2}$ significantly decreased at the beginning of the anastomosis in all three coronary arteries although the MAP was constantly maintained throughout the procedure. In the OM and RCA, immediately after snaring the pericardial bands for stabilization CI and $\mathrm{SvO}_{2}$ decreased abruptly, but further decrease did not occur. However, the cardiac index was decreased in linear fashion with time during LAD anastomosis. Compression of the left ventricular outflow tract and abnormal diastolic expansion secondary to direct deformation of the left ventricular geometry are proposed mechanisms for hemodynamic derangements with compression type stabilizer. Coronary occlusion during the anastomosis can have additional effects on left ventricular function, depending on the status of collateral flow [8].

During anastomosis of anterior arteries such as LAD coronary artery target stabilization results in direct compression of the right ventricular outflow tract and the right ventricular end systolic and diastolic volumes increase. As a result, the left ventricular diastolic compliance is reduced through the interventricular relationship and the PAP and PCWP increase [13]. During LAD anastomosis, the obstruction of the right ventricular outflow tract may be the possible reason for the gradual decrease in $\mathrm{CI}$, although reduction in blood supply to the large portion of left ventricular myocardium with impaired global ventricular function might have contributed, especially if intracoronary shunt was not used.

During OPCAB the sustained hemodynamic compromise may adversely affect major organ function, especially if the total time required for anastomosis is prolonged. The grafting of the posterior coronary branches (OM and posterior descending artery) through sternotomy requires anterior displacement of the beating heart and this often causes hemodynamic compromise $[14,15]$. The sustained decrease in CI $(<2.01 / \mathrm{min})$ and $\mathrm{SvO}_{2}(<70 \%)$ during whole period of OM anastomosis should warn of impending major organ damage though none of patients, in this study, had developed neurologic complications or an evidence of organ damage. If high risk patients are subjected to OPCAB the sustained or repetitive low cardiac output status might have deleterious effect on organ function, therefore, it is increasingly necessary to adequately monitor and manage variables like $\mathrm{CI}$, and $\mathrm{SvO}_{2}$. The $\mathrm{SvO}_{2}$ represents both delivery and consumption of oxygen and changes earlier compared to the continuous cardiac output measurements. Though the changes in cardiac output might be too slow to monitor the cardiac status during the manipulation and tilting of the heart, it is still a useful variable as a trend during the entire surgical period.

The optimal management of patients undergoing OP$\mathrm{CAB}$ has been focused on the maintenance of stable hemodynamics such as MAP, HR and cardiac rhythm as well adequate tissue perfusion during coronary anastomosis [16-18]. The intravenous fluid loading and head down position were often used to compensate decreased MAP and CO while the use of inotropic drugs was relatively contraindicated [19]. The mechanical displacement and compression of the heart during anastomosis results in decrease in the $\mathrm{CI}$ and use of inotropic drugs may further increase myocardial oxygen consumption and induces myocardial ischemia [20-22]. In the study, it was found that the augmentation of preload with head down position and fluid loading was not adequate enough to compensate the reduced $\mathrm{CO}$ during anastomosis. There- 
fore, management to maintain the $\mathrm{CO}$ and $\mathrm{SvO}_{2}$ without subsequent adverse cardiac effects is essential and inotropic drugs that would not adversely increase chronotopism of the heart and myocardial oxygen consumption may be useful $[22,23]$.

In conclusion, this study represents our experience using four deep pericardial stay sutures and pericardial bands for coronary artery target stabilization, recording serial hemodynamic changes occurred during $\mathrm{OPCAB}$ surgery. Other techniques using mechanical stabilizers, slings and tapes to expose and stabilize the coronary vessel may result in similar magnitude of hemodynamic changes which are largely dependent on the surgical technique and surgeon's skill. Though HR and MAP were maintained constantly throughout the procedure, $\mathrm{SvO}_{2}$ and $\mathrm{CI}$ decreased significantly at the beginning of $\mathrm{OM}$ and RCA anastomosis, and maintained constantly throughout, while the CI and $\mathrm{SvO}_{2}$ decreased further as a function of time during LAD anastomosis. Therefore, close monitoring with adequate interventions are necessary to prevent decreases in $\mathrm{CI}$ and $\mathrm{SvO}_{2}$ and avoiding conversion to on-pump technique.

\section{REFERENCES}

[1] M. J. Mack, A. Pfister, D. Bachand, R. Emery, M. J. Magee, M. Connolly, et al., "Comparison of Coronary Bypass Surgery with and without Cardiopulmonary Bypass in Patients with Multivessel Disease," Journal of Thoracic and Cardiovascular Surgery, Vol. 127, No 1, 2004, pp. 167-173.

http://dx.doi.org/10.1016/j.jtcvs.2003.08.032

[2] K. V. Arom, T. F. Flavin, R. W. Emery, V. R. Kshettry, P. A. Janey and R. J. Petersen, "Safety and Efficacy of Off-Pump Coronary Artery Bypass Grafting," Annals of Thoracic Surgery, Vol. 69, No. 3, 2000, pp. 704-710. http://dx.doi.org/10.1016/S0003-4975(99)01510-6

[3] T. Yokoyama, F. J. Baumgartner, A. Gheissari, E. R. Capouya, G. P. Panagiotides and R. J. Declusin, "OffPump versus On-Pump Coronary Bypass in High Risk Subgroups," Annals of Thoracic Surgery, Vol. 70, No. 5, 2000, pp. 1546-1550. http://dx.doi.org/10.1016/S0003-4975(00)01922-6

[4] S. Al-Ruzzeh, S. George, M. Yacoub and M. Amrani, "The Clinical Outcome of Off-Pump Coronary Artery Bypass Surgery in the Elderly Patients," European Journal of Cardiothoracic Surgery, Vol. 20, No. 6, 2001, pp. 1152-1156.

http://dx.doi.org/10.1016/S1010-7940(01)00978-2

[5] J. D. Puskas, W. H. Williams, P. G. Duke, J. R. Staples, K.E. Glas, J. J. Marshall, et al., "Off-Pump Coronary Artery Bypass Grafting Provides Complete Revascularization with Reduced Myocardial Injury, Transfusion Requirements, and Length of Stay: A Prospective Randomized Comparison of Two Hundred Unselected Patients Undergoing Off-Pump versus Conventional Coronary Artery Bypass Grafting," Journal of Thoracic and Car- diovascular Surgery, Vol. 125, No. 4, 2003, pp. 797-808. http://dx.doi.org/10.1067/mtc.2003.324

[6] T. H. Spooner, J. C. Hart and J. Pym, "A Two-Year, Three Institution Experience with the Medtronic Octopus: Systematic Off-Pump Surgery," Annals of Thoracic Surgery, Vol. 68, No. 4, 1999, pp. 1478-1481. http://dx.doi.org/10.1016/S0003-4975(99)00966-2

[7] P. F. Gründeman, C. Borst, J. A. van Herwaarden, C. W. Verlaan and E. W. Jansen, "Vertical Displacement of the Beating Heart by the Octopus Tissue Stabilizer: Influence on Coronary Flow," Annals of Thoracic Surgery, Vol. 65, No. 5, 1998, pp. 1348-1352. http://dx.doi.org/10.1016/S0003-4975(98)00226-4

[8] C. Pierre, D. Andre, L. Patrick, S. Peter, B. Denis and C. Raymond, "Mechanisms of Hemodynamic Changes during Off-Pump Coronary Artery Bypass Surgery," Canadian Journal of Anesthesia, Vol. 49, No. 8, 2002, pp. 835849. http://dx.doi.org/10.1007/BF03017418

[9] J. Bergsland, H. L. Karamanoukian, P. R. Soltoski and T. A. Salerno, "'Single Suture' for Circumflex Exposure in Off-Pump Coronary Artery Bypass Grafting," Annals of Thoracic Surgery, Vol. 68, No. 4, 1999, pp. 1428-1430. http://dx.doi.org/10.1016/S0003-4975(99)00935-2

[10] S. Sirivella and I. Gielchinsky, "Cardiac Immobilization in Beating Heart Surgery Using Pericardial Bands," World Journal of Cardiovascular Surgery, Vol. 2, No. 2, 2012, pp. 14-16. http://dx.doi.org/10.4236/wjcs.2012.22005

[11] F. J. Benetti, C. Naselli, M. Wood and L. Geffiner, "Direct Myocardial Revascularization without Extracoporeal Circulation. Experience in 700 patients," Chest, Vol. 100, No. 2, 1991, pp. 312-316. http://dx.doi.org/10.1378/chest.100.2.312

[12] J. M. Hemli, N. C. Patel and V. A. Subramanian, "Increasing Surgical Experience with off Pump Coronary Surgery Does Not Mitigate the Morbidity of Emergency Conversion to Cardiopulmonary Bypass," Innovations, Vol. 7, No. 4, 2012, pp. 259-265. http://dx.doi.org/10.1097/IMI.0b013e31826f0d7a

[13] Q. B. Do, C. Goyer, O. Chavanon, P. Couture, A. Denault and R. Cartier, "Hemodynamic Changes during OffPump CABG Surgery," European Journal of Cardiothoracic Surgery, Vol. 21, No. 3, 2002, pp. 385-390. http://dx.doi.org/10.1016/S1010-7940(02)00009-X

[14] T. W. Koh, G. S. Carr-White, A. C. DeSouza, F. D. Ferdinand, J. Hooper, M. Kemp, et al., "Intraoperative Cardiac Troponin T Release and Lactate Metabolism during Coronary Artery Surgery: Comparison of Beating Heart with Conventional Coronary Artery Surgery with Cardiopulmonary Bypass," Heart, Vol. 81, No. 5, 1999, pp. 495-500.

[15] A. M. Calafiore, M. DiMauro, M. Contini, G. DiGiammarco, M. Pano and G. Vitolla, "Myocardial Revascularization with and without Cardiopulmonary Bypass in Multivessel Disease: Impact of the Strategy on Early Outcome," Annals of Thoracic Surgery, Vol. 72, No. 2, 2001, pp. 456-463. http://dx.doi.org/10.1016/S0003-4975(01)02810-7

[16] T. Yamada, J. Takeda, N. Katori, K. Tsuzaki and R. 
Ochiai, "Hemodynamic Effects of Milrinone during Weaning from Cardiopulmonary Bypass: Comparison of Patients with a Low and High Prebypass Cardiac Index," Journal of Cardiothoracic and Vascular Anesthesia, Vol. 14, No. 4, 2000, pp. 367-373. http://dx.doi.org/10.1053/jcan.2000.7920

[17] E. S. Monrad, D. S. Baim, H. S. Smith, A. S. Lanoue, E. Braunwald and W. Grossman, "Effects of Milrinone on Coronary Hemodynamics and Myocardial Energetics in Patients with Congestive Heart Failure," Circulation, Vol. 71, No. 5, 1985, pp. 972-979. http://dx.doi.org/10.1161/01.CIR.71.5.972

[18] T. Turk, Y. Ata, H. Vural, H. Ozkan, S. Yavuz and A. Ozyazicioglu, "Intravenous and Oral Amiodarone for the Prevention of Postoperative Atrial Fibrillation in Patients Undergoing Off-Pump Coronary Arterybypass Surgery," Heart Surgery Forum, Vol. 10, No. 4, 2007, pp. E299E303. http://dx.doi.org/10.1532/HSF98.20071060

[19] P. F. Gründeman, C. Borst, C. W. Verlaan, H. Meijburg, C. M. Moues and E. W. Jansen, "Exposure of Circumflex Branches in the Tilted, Beating Porcine Heart: Echocardiographic Evidence of Right Ventricular Deformation and the Effect of Right or Left Heart Bypass," Journal of Thoracic and Cardiovascular Surgery, Vol. 118, No. 2, 1999, pp. 316-323.
http://dx.doi.org/10.1016/S0022-5223(99)70222-9

[20] F. G. Resano, S. C. Stamou, R. C. Lowery and P. J. Corso, "Complete Myocardial Revascularization on the Beating Heart with Epicardial Stailization: Anesthetic Considerations," Journal of Cardiothoracic and Vascular Anesthsia, Vol. 14, No. 5, 2000, pp. 534-539. http://dx.doi.org/10.1053/jcan.2000.9452

[21] W. R. Burfeind, F. G. Duhaylongsod, D. Samuelson and B. J. Leone, "The Effects of Mechanical Cardiac Stabilization on Left Ventricular Performance," European Journal of Cardiothoracic Surgery, Vol 14, No. 3, 1998, pp. 285-289. http://dx.doi.org/10.1016/S1010-7940(98)00199-7

[22] E. S. Monrad, D. S. Baim, H. S. Smith and A. S. Lanoue, "Milrinone, Dobutamine, and Nitroprusside: Comparative Effects on Hemodynamics and Myocardial Energetics in Patients with Severe Congestive Heart Failure," Circulation, Vol. 73, No III, 1986, pp. 168-174.

[23] B. Axelson, M. Arbeus, A. Magnuson and J. Hultman, "Milrinone Improves Diastolic Function in Coronary Artery Bypass Surgery as Assessed by Acoustic Quantification and Peak Filling Rate: A Prospective Randomized Study," Journal of Cardiothoracic and Vascular Anesthesia, Vol. 24, No. 2, 2010, pp. 244-249.

http://dx.doi.org/10.1053/j.jvca.2009.10.007 